04

\title{
Синтез пленок нанокристаллического графита в разряде с полым катодом
}

\author{
() И.А. Сорокин, ${ }^{1,2}$ Д.В. Колодко, ${ }^{1,2}$ Е.Г. Шустин ${ }^{1,2}$ \\ ${ }^{1}$ Фрязинский фрилиал Института радиотехники и электроники им. В.А. Котельникова РАН, \\ 141190 Фрязино, Московская обл., Россия \\ ${ }^{2}$ Национальный исследовательский ядерный университет „МИФИ“, \\ 115409 Москва, Россия \\ e-mail: iasorokin@mail.ru
}

(Поступило в Редакцию 29 декабря 2017 г.)

\begin{abstract}
Представлены результаты экспериментов по получению пленок нанокристаллического графита в тлеющем разряде с полым катодом на подложку $\mathrm{Ni}(111)$ на сапфире. Приведены характеристики разряда для разных газов и давлений, измерены эмиссионные спектры плазмы и проведена характеризация получаемых слоев с помощью методов комбинационного рассеяния и атомно-силовой микроскопии. Также измерена автоэлектронная эмиссия нанокристаллического графита. Полученные слои обладают хорошей однородностью, высокой автоэлектронной эмиссией. Выявлено наличие вертикально растущего графена.
\end{abstract}

DOI: 10.21883/JTF.2018.08.46307.2629

\section{Введение}

Начиная с 90-х годов прошлого столетия, углеродные материалы привлекают все большее внимание с точки зрения их использования в электронике, начиная с достаточно простых радиаторов силовой электроники и заканчивая сложными дисплеями с большой площадью плоской панели. Каждое из этих потенциальных приложений зависит от возможности производства высококачественных, воспроизводимых материалов с полностью определенными свойствами; при этом каждое конкретное приложение предъявляет свои требования. Из этих потенциальных материалов тонкая пленка аморфного углерода обладает многими привлекательными свойствами для электронных применений: запрещенная зона, которая может варьировать от $\sim 0.5$ до $\sim 4.0 \mathrm{eV}$, возможность получения $p$ - и $n$-проводимости, возможность осаждения на большой площади при комнатной температуре. Аморфный углерод, содержащий значительные количества кластеров с sp3-связями, получил название алмазоподобный углерод (DLC). Именно эти кластеры придают алмазоподобному углероду свойства химической инертности, механической твердости и более широкую запрещенную зону, чем материал с преобладанием связей $s p 2[1,2]$. Материал с высоким содержанием sp3связей из-за его большого процента тетраэдрического связывания известен как аморфный углерод с тетраэдрическим связыванием (Та-С). Та-С можно выращивать различными методами, в том числе с использованием энергичных ионов или плазмы.

Однако использование тонких пленок аморфного углерода в электронных устройствах было ограничено высокой плотностью дефектов и связанными с ними низкими подвижностями. Их основное применение в электронике - в качестве электронных эмиттеров (холодных катодов), где большое внимание привлекло присущее им низкое пороговое поле [3].

Здесь мы предлагаем новый способ осаждения аморфных углеродных пленок, отличающийся простотой конструкции источника плазмы и легкостью вариации толщины осаждаемой пленки. Осажденные таким способом пленки обладают, как оказалось, необычной структурой поверхности.

\section{Характеристика разряда}

Осаждение графитовых слоев на используемые подложки осуществляется в разряде с полым катодом в атмосфере пропана. Эксперименты поводились на вакуумном стенде объемом 51, откачиваемом с помощью вакуумного агрегата АВДМ-100 до остаточного давления $10^{-3} \mathrm{~Pa}$. Модель катода/держателя образцов и фотографии разряда в режиме тлеющего разряда (ТР) и разряда с полым катодом (РПК) представлены на рис. 1.

Полый катод образован двумя круглыми пластинами диаметром $25 \mathrm{~mm}$, расположенными на расстоянии $5 \mathrm{~mm} \mathrm{1}$, образец располагается в углублении одной из пластин 3. Катод электрически изолирован с помощью керамической трубки. Потенциал на катод подается относительно заземленной стенки вакуумной камеры (анод).

Для определения границ перехода ТР в РПК в данной конфигурации были сняты вольт-амперные характеристики (BAX) разряда для различных значений рабочего давления. На рис. 2 представлены примеры ВАХ разряда на аргоне для различных давлений.

При подаче потенциала на катод наблюдается монотонное увеличение тока разряда и слабое свечение вокруг электрода - ТР (рис. 1, $b$ (верх)). По достижении определенного значения напряжения, которое зависит от 
рабочего давления, происходит переход разряда в режим РПК, характеризующийся резким скачком тока в цепи и увеличением интенсивности свечения внутри полого катода (рис. $1, b$ (низ)). При низком давлении 1 монотон-
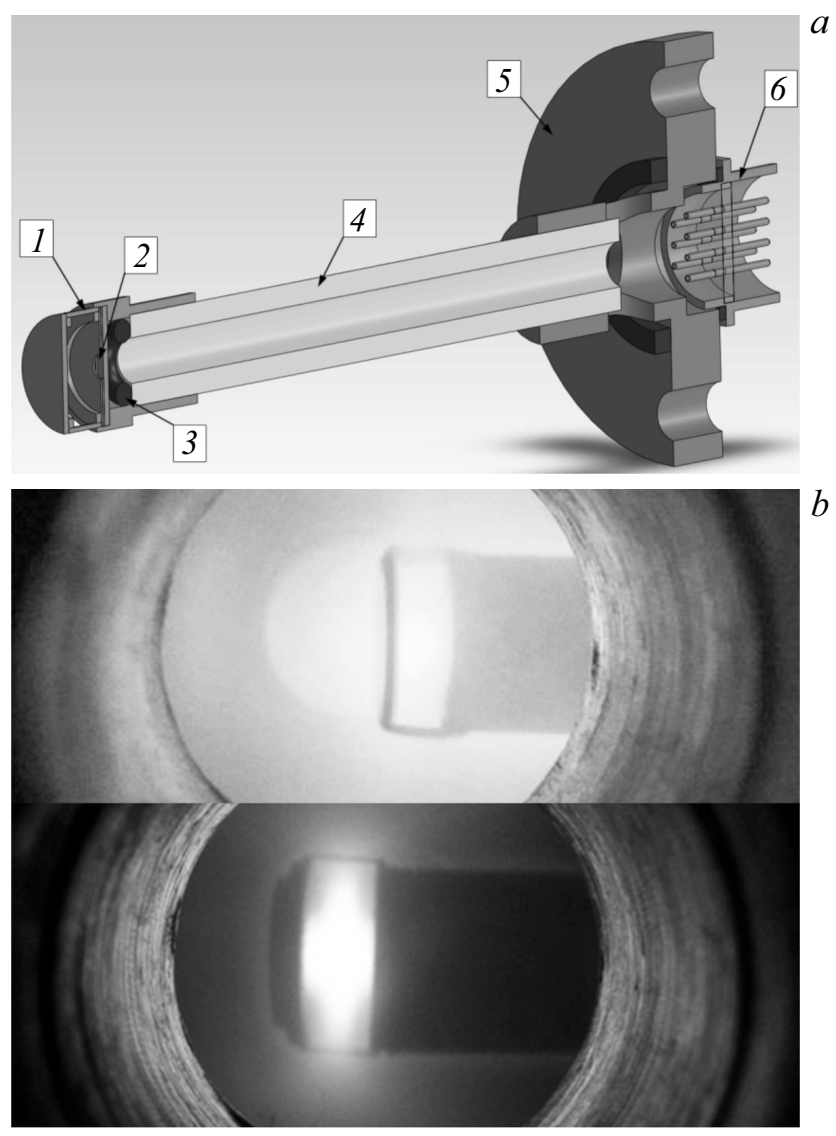

Рис. 1. Катод-держатель образца в разрезе $(a)$ и общий вид разряда $(b): 1$ - катод-держатель образца, 2 - образец, 3 нагреватель, 4 - керамическая трубка, 5 - фланец, $6-$ электрический ввод.

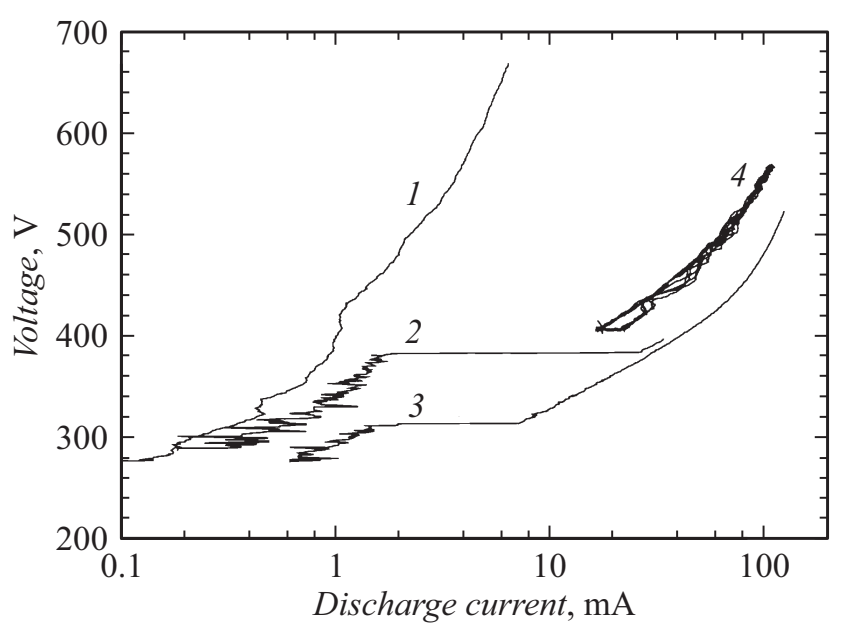

Рис. 2. ВАХ разряда для различных рабочих давлений: $1-3-$ разряд в аргоне при давлении $9(1), 12$ (2) и $16 \mathrm{~Pa}(3) ; 4-$ в пропане $(p=27 \mathrm{~Pa})$.

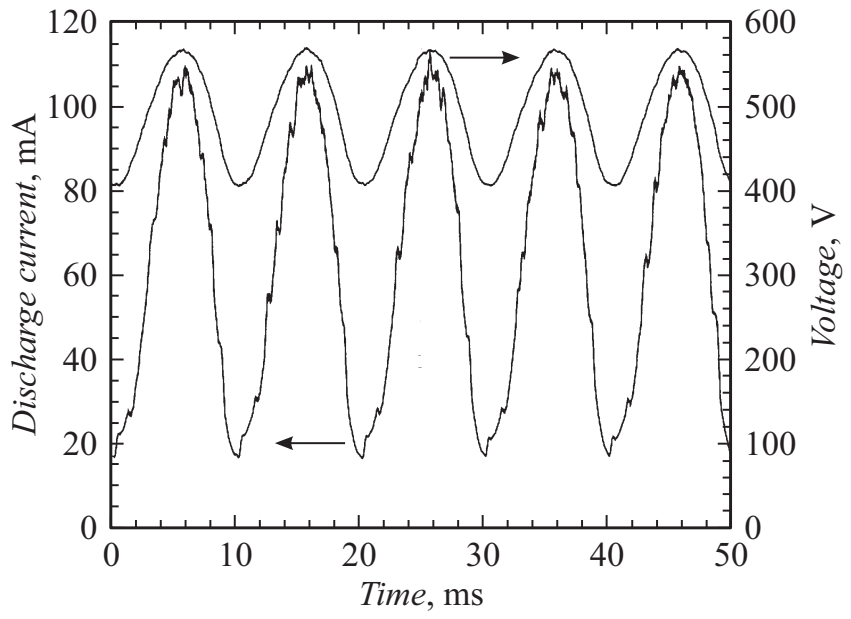

Рис. 3. Зависимость тока и напряжения РПК от времени при напылении нанокристаллического графита.

ный рост наблюдается в широком диапазоне напряжений разряда и перехода в РПК не происходит, что связано с низкой эффективностью ионизации электронов, осциллирующих внутри полого катода. Характеристика в режиме РПК практически не зависит от давления в широком диапазоне [4].

В процессе нанесения углеродных слоев в РПК с использованием стабилизированных блоков постоянного тока/напряжения наблюдаются частые пробои на поверхности катода, приводящие к образованию микродуг и связанные с развитием рельефа поверхности образца во время осаждения углерода. Часто для подавления таких нестабильностей, которые приводят к неоднородности получаемых слоев и дефектам подложки, используется периодический или импульсно-периодический источник тока/напряжения [5]. Для того чтобы избежать таких нестабильностей, в настоящей работе использовался блок питания переменного напряжения, смещенного на величину напряжения разряда относительно анода. На рис. 3 представлена зависимость от времени тока и напряжения РПК в атмосфере пропана в процессе нанесения углеродных слоев. ВАХ 4 на рис. 2 соответствует разряду на пропане в процессе осаждения.

В процессе нанесения графитового покрытия было необходимо контролировать уровень кислорода и воды для исключения роста оксидной пленки на поверхности подложки. Для контроля состава плазмы РПК использовался обзорный спектрометр AvaSpec-2048x14. Интенсивность полосы воды и линий кислорода в экспериментах были незначительными по сравнению с основными линиями углеводородов.

\section{Методика нанесения и характеризация покрытия}

Образцы $\mathrm{Al}_{2} \mathrm{O}_{3} / \mathrm{Ni}(111)$ помещаются в вакуумную камеру, которая откачивается до давления $10^{-3} \mathrm{~Pa}$. Затем 

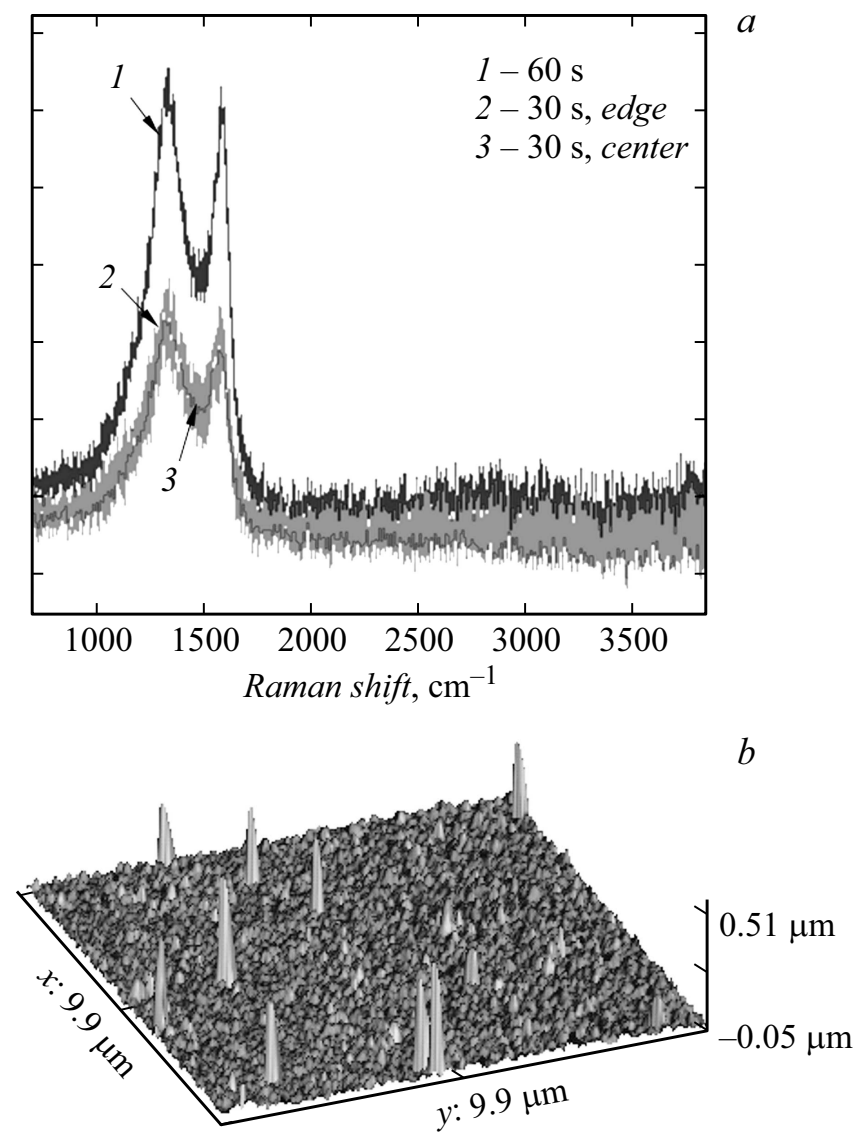

Рис. 4. Рамановские спектры $(a)$ и трехмерное изображение поверхности напыленного графита, полученное с помощью $\operatorname{ACM}(b)$.

для восстановления оксидной пленки на поверхности $\mathrm{Ni}$ проводится отжиг образца в атмосфере водорода при давлении $1 \mathrm{~Pa}$ и температуре $400^{\circ} \mathrm{C}$ в течение $10 \mathrm{~min}$. Далее напускается пропан ПТ (ГОСТ 20448-90) до давления 10 Ра и зажигается тлеющий разряд с полым катодом. Осаждение графита происходит в течение 10-60s. Опытным путем была определена оптимальная температура для формирования нанокристаллического графита $-600^{\circ} \mathrm{C}$. Остывание образца проводилось в смеси газов (водород и пропан) при давлении $100 \mathrm{~Pa}$.

Анализ кристаллической структуры, толщины и структуры поверхности полученных слоев осуществляется с помощью раман-микроспектрометра RamMics (OOO „ИнСпектр“, Черноголовка, Россия) и атомно-силового микроскопа (АCM) SmartSPM (OOO „АИСТ“, Зеленоград, Россия). На рис. 4 представлен рамановский спектр и АСМ-образ поверхности полученной пленки графита.

Форма спектра комбинационного рассеяния (рис. 4, a) практически однородна по поверхности и соответствует спектру нанокристаллического графита [6]. Спектры комбинационного рассеяния для серий образцов одинаковой обработки показали хорошую повторяемость процесса нанесения. Толщина получаемых слоев 200-700 nm была измерена с помощью АСМ по пере- паду высот между поверхностью монокристаллического никеля, закрытого от РПК, и поверхности получаемых слоев; среднее значение шероховатости (RMS) образцов составило 10-15 nm. Также с помощью АCM на поверхности были обнаружены вертикально растущие графеновые острия. Толщина образований меньше толщины зонда ACM (на рисунке - результат свертки изображения острия и зонда микроскопа).

Нанокристаллический графит сам по себе является перспективным автоэмиссионным материалом для изготовления катодов. Наличие вертикально растущих игл графена на поверхности позволило предположить значительное увеличение эмиссионной способности. Действительно, исследование эмиссионной способности образцов, проведенное на стенде, описанном в [7], показало, что плотность тока составляет в среднем $900 \mu \mathrm{A} / \mathrm{cm}^{2}$ при напряженности электрического поля $10 \mathrm{kV} / \mathrm{mm}$, что сравнимо со значениями для современных образцов автокатодов [8-10]. Величина эмиссии стабильна по времени и хорошо воспроизводима.

\section{Заключение}

Разработана методика получения пленок нанокристаллического графита путем осаждения углерода из газовой фазы в разряде с полым катодом на образцы $\mathrm{Al}_{2} \mathrm{O}_{3} / \mathrm{Ni}(111)$. Такие пленки могут в дальнейшем использоваться для отработки режимов гетероэпитаксиального синтеза структурно однородного графена для наноэлектроники [11]. Методика показала хорошую воспроизводимость, что подтверждается измерениями с помощью рамановского спектрометра и АСМ. Оценена эмиссионная способность поверхности получаемых пленок. Значения плотности тока с нанокристаллического графита с „иглами“ графена на поверхности сравнимы со значениями для современных образцов автокатодов, что позволяет использовать подобный материал для изготовления автоэмиссионных катодов.

Авторы благодарят М.П. Тимирязеву за АСМ характеризацию поверхности образцов и Д.Н. Синельникова за оценку эмиссионной способности нанокристаллического графита.

Работа выполнена при частичной поддержке Программы повышения конкурентоспособности НИЯУ МИФИ.

\section{Список литературы}

[1] Robertson J. // Matertal Sci. Engineering. 2002. Vol. 37. N 4-6. P. 129-282.

[2] Milne W.I. // Semicond. Sci. Technol. 2003. Vol. 18. N 3. P. S81-S85.

[3] Milne W.I., Robertson J., Satyanarayana B.S., Hart A. // Int. J. Mod. Phys. 2000. Vol. 14. N 2-3. P. 301-307.

[4] Москалев Б.И. Разряд с полым катодом. М.: Энергия, 1969. $184 \mathrm{c}$. 
[5] Borisyuk Y.V., Oreshnikova N.M., Mozgrin D.V., Stepanova T.V., Pisarev A.A. // J. Physics: Conf. Series. 2016. Vol. 747. N 1.

[6] Chu P.K., Li L. // Mater. Chem. Phys. 2006. Vol. 96. N 2-3. P. 253-277.

[7] Sinelnikov D.N., Kurnaev V.A., Mamedov N.V. // J. Surf. Investigation. 2015. Vol. 9. N 6. P. 1281-1286.

[8] Zhai C.X., Zhang Z.Y., Zhao L.L., Wang X.W., Zhao W. // Thin Sol. Films. 2015. Vol. 574. P. 10-14.

[9] Ha J.M., Kim H.J., Raza H.S., Cho S.O. // Nanoscale Research Letters. 2013. Vol. 8. N 1. P. 1-8.

[10] Xu N.S., Chen Y., Deng S.Z., Chen J., Ma X.C., Wang E.G. // J. Physics D: Appl. Phys. 2001. Vol. 34. N 11. P. 1597-1601.

[11] Шустин Е.Г., Исаев Н.В., Лузанов В.А., Темирязева М.П. // ЖТФ. 2017. Т. 87. Вып. 7. С. 1053-1056. 